\title{
Continuous extrapleural intercostal nerve block after pleurectomy
} Everett J Mozell, Sabaratnam Sabanathan, Alan J Mearns, Philip J Bickford-Smith,
Mohammed R Majid, George Zografos

\begin{abstract}
A randomised, double blind trial was carried out in 16 patients undergoing pleurectomy to assess the effect of continuous extrapleural intercostal block on postoperative pain and pulmonary function. Subjective pain relief was assessed on a linear visual analogue scale. Pulmonary function was measured on the day before operation and daily for five days after surgery. Eight patients received bupivacaine and eight placebo (saline). The mean pain scores at $4,8,16$, and 24 hours were $13.3,8 \cdot 5,6 \cdot 1$, and $10 \mathrm{~mm}$ respectively in the bupivacaine group compared with $56 \cdot 3,41,46 \cdot 7$, and 35 in the control group; in addition, the bupivacaine group required less papaveretum. Twenty four hours after surgery mean values of peak expiratory flow, forced expiratory volume in one second, and forced vital capacity were reduced to $82 \%, 76 \%$, and $76 \%$ of preoperative control values in the bupivacaine group, and to $39 \%, 32 \%$, and $36 \%$ in the control group. The speed of recovery of pulmonary function was superior in the bupivacaine group. There were no complications related to the infusion. Continuous extrapleural intercostal nerve blockade with bupivacaine provides safe and effective postoperative analgesia and improves respiratory mechanics after pleurectomy.
\end{abstract}

Spontaneous pneumothorax may be primary (idiopathic) or secondary to underlying pulmonary disease. Spontaneous pneumothorax usually occurs in the third and fourth decades of life from rupture of a subpleural bleb, ${ }^{1}$ and it resolves with observation or tube drainage in $80-90 \%$ of cases. ${ }^{2}$ A parietal pleurectomy is indicated for recurrent pneumothoraces (three ipsilateral pneumothoraces) and a first contralateral pneumothorax, and for failure to respond adequately to management by tube drainage,${ }^{1-3}$ if the patient is fit enough for a thoracotomy.

Thoracotomy causes severe postoperative pain and considerable impairment of pulmonary function. ${ }^{4}$ These changes are worst in the elderly, the obese, smokers, and those with pre-existing cardiopulmonary disease. ${ }^{5}$ Pain after operation is the most important factor responsible for ineffective ventilation and coughing and for the impaired ability to breathe deeply and sigh in these patients. This leads to atelectasis, hypoxaemia, infection, and respiratory distress. ${ }^{67}$

Continuous extrapleural intercostal nerve block provides effective analgesia after elective thoracotomy, minimises the expected decline in lung function at 24 hours, and improves the subsequent restoration of lung function. ${ }^{8}$ Our original description of the technique of continuous extrapleural intercostal nerve block referred to patients with intact pleura. ${ }^{9}$ The present study was undertaken to assess the effects of continuous intercostal nerve block on postoperative pain and pultive parietal pleurectomy.

\section{Methods}

All patients undergoing elective pleurectomy were admitted to the trial. The study was approved by the ethics committee of the from all patients. Patients were given preoperative instruction in the use of the hand held spirometer (Respiradyne, ChesebroughPond's Ltd, Greenwich) ${ }^{10}$ and the linear visual analogue scale. All patients had a standard anaesthetic with a double lumen endobronchial tube and single lung ventilation.

\section{PLEURECTOMY}

A parietal pleurectomy was performed through a limited posterolateral thoracotomy. The technique of pleurectomy followed Gaensler's original description, ${ }^{11}$ except that the parietal pleura over the paravertebral space extending from the angle of the rib to the vertebral bodies was left intact.

\section{THE INFUSIONS}

A percutaneous epidural cannula was inserted during operation into the pleura covered paravertebral space and positioned in the appropriate intercostal space. ${ }^{89}$ The cannula was fitted with a bacterial filter. Patients were randomly allocated to receive an extrapleural infusion of saline (control group) or $0.5 \%$ bupivacaine (treatment group). Twenty millilitres of the randomised infusate was given before the anaesthetic was reversed; the nature of the infusate was known to the operator. On returning to the ward patients received a continuous infusion of $0.5 \%$ bupivacaine or saline according to weight ( $5 \mathrm{ml} / \mathrm{h}$ for patients weighing $50-59 \mathrm{~kg}, 6 \mathrm{ml} /$ h for $60-69 \mathrm{~kg}, 7 \mathrm{ml} / \mathrm{h}$ for $70-79 \mathrm{~kg}, 8 \mathrm{ml} / \mathrm{h}$ for $80-89 \mathrm{~kg}, 9 \mathrm{ml} / \mathrm{h}$ for $90-99 \mathrm{~kg}$, and monary function in patients undergoing elechospital and informed consent was obtained
BD9 6RJ

Reprint requests to: Mr Sabanathan

Accepted 20 October 1990 
Table 1 Characteristics of patients

\begin{tabular}{lcc}
\hline & Group receiving & \\
\cline { 2 - 3 } & Bupivacaine & Saline \\
\hline Mean (range) age (years) & $38 \cdot 3(21-53)$ & $30(17-48)$ \\
Sex (M:F) & $6: 2$ & $6: 2$ \\
Spontaneous pneumothorax & 4 & 5 \\
$\quad$ Primary & 4 & 3 \\
Secondary & $5 / 3$ & $4 / 4$ \\
Left/right thoracotomy & $79(9)$ & $69(9)$ \\
Mean (SD) body weight (kg) & & $3 \cdot 41(0 \cdot 35)$ \\
Mean (SD) preoperative values & $3 \cdot 66(0 \cdot 91)$ & $4 \cdot 39(0 \cdot 5)$ \\
FEV (L) & $4 \cdot 61(0 \cdot 74)$ & $485(43)$ \\
FVC (L) & $484(53)$ & \\
PEF (L.Min $\left.{ }^{-1}\right)$ &
\end{tabular}

$10 \mathrm{ml} / \mathrm{h}$ for $100 \mathrm{~kg}$ and over). The infusate was prepared for each patient by the pharmacy department. The infusions were continued until the morning of the fifth postoperative day. This did not restrict patients' mobility as the infusion pump was portable and could be disconnected for short periods.

The randomisation code was available to the investigators at all times in case of emergency. Staff taking measurements and setting up the infusions were not told which infusate was being given.

\section{OTHER ANALGESIA}

All the patients had access on request to intramuscular papaveretum (10-15 mg according to weight) or rectal diclofenac sodium, or both, during the first 48 hours and thereafter to oral co-codamol or rectal diclofenac sodium, or both. No attempt was made to withhold requested analgesic.

\section{POSTOPERATIVE ASSESSMENT}

Postoperative pain was assessed by the patients on a $10 \mathrm{~cm}$ ungraded linear visual analogue scale. The left hand margin had a score of zero, representing no pain, and the right hand margin a score of 10 , representing the worst pain imaginable. Pain scores were recorded when the patient recovered from the anaesthetic and $1,4,8,16,24,32,48,72$, and 120 hours after surgery. The requirement for analgesia was recorded for each patient. Before operation and each morning during the first five postoperative days peak expiratory flow (PEF), forced expiratory volume in one second $\left(\mathrm{FEV}_{1}\right)$, and forced vital capacity (FVC) were measured with the patient in the sitting position. The best of three measurements was recorded.

PEF, FEV 1 , and FVC were expressed as percentages of the preoperative values. Parametric data were analysed by means of the Kruskall-Wallis one way analysis of variance by ranks and non-parametric data by the Mann-Whitney U test.

\section{Results}

The two groups of patients were similar in age distribution, sex ratio, smoking habits, body weight, height, and site and type of operation Patients' charcteristics and surgical procedures are summarised in table 1 . No complications related to the infusion occurred.

Throughout the study period the bupivacaine group had better pain relief as determined by linear analogue pain scores ( $p<0.01$ at 18 hours and $<0.05$ at 24 hours (fig 1) and by their lesser need for postoperative papaveretum ( $<<0.01$ : table 2 ). Only one patient in the bupivacaine group but all except one in the saline group needed rectal diclofenac sodium.

Mean (SEM) values of $\mathrm{FEV}_{1}, \mathrm{FVC}$, and PEF, as percentages of preoperative control values, at 24 hours fell to $76(3 \cdot 4), 76(2 \cdot 6)$ and $82(5.9)$ in the bupivacaine group and to 32
Figure 1 Pain scores (means with SEM) during the first five postoperative days. The accumulated pain scores were significantly lower throughout the study period $(p<0.01$ and $<0.05$ at 18 and 24 hours) in the group receiving bupivacaine than in those having saline.

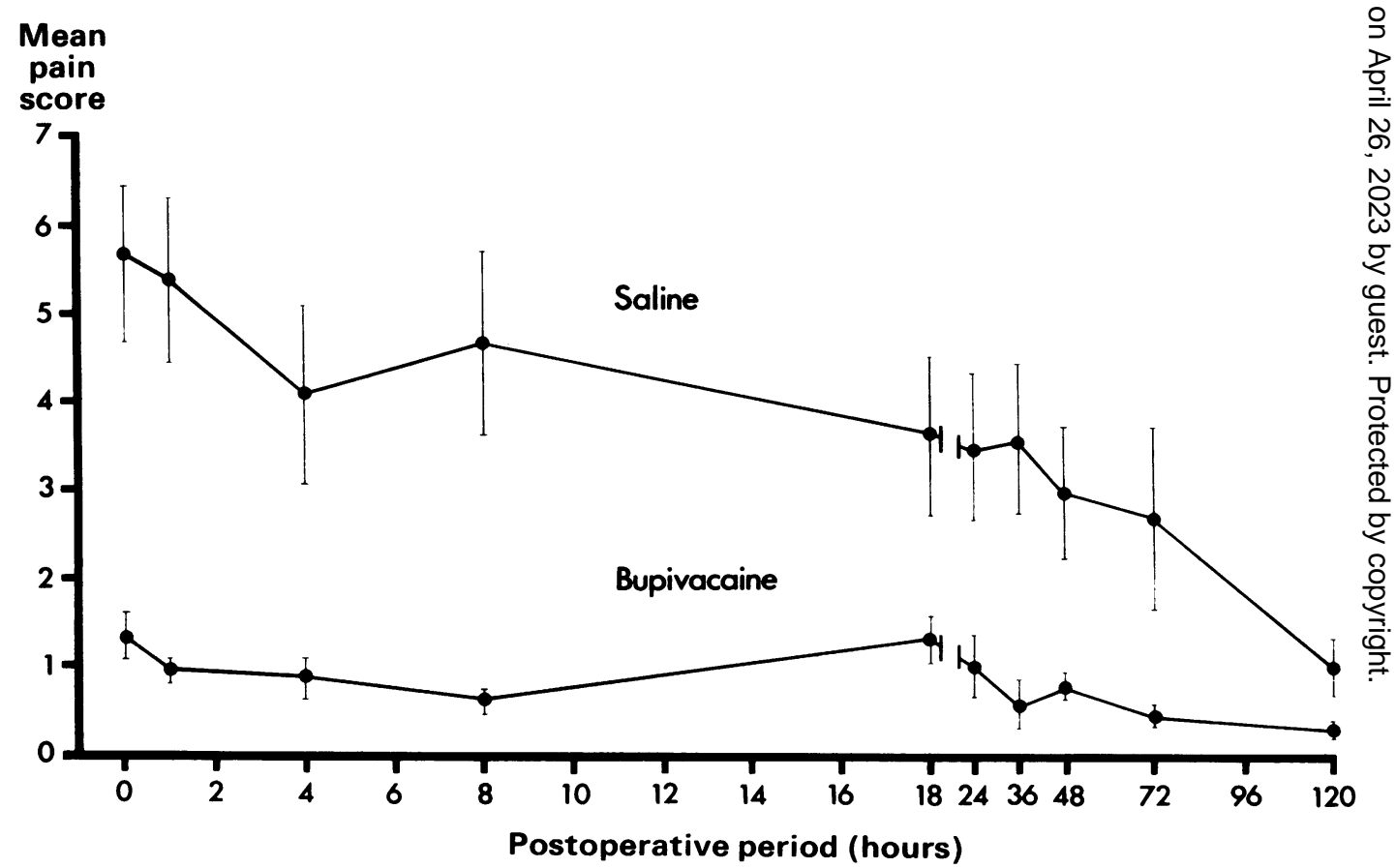


$(5 \cdot 5), 36(5 \cdot 1)$, and $39(5 \cdot 3)$ in the saline group (fig 2 ). The differences were highly significant $(\mathrm{p}<0.01)$. These values had returned to two thirds $(67 \%)$ of their preoperative values by day 5 in the control group, whereas all values had returned to normal by day 3 in the bupivacaine group and they exceeded the baseline values during the remainder of the study period. Although the $\mathrm{FEV}_{1}, \mathrm{FVC}$, and PEF in both groups improved each day, values in the bupivacaine group were better at each time of measurement $(p<0.01)$. No pulmonary complications occurred.

Figure 2 Lung function values (means with SEM) in the first five days after thoracotomy, plotted as percentages of preoperative values, showing significant differences between the groups receiving

bupivacaine and saline. (a) FEV : for rate of recovery $p<0.01$. (b)

Forced vital capacity: for percentage reduction $p<0.01$. (c) Peak expiratory flow (PEF): for reduction at 24 hours $p<0.01$ and for restoration of function $p<0.01$

FEV

(\% change

from baseline)

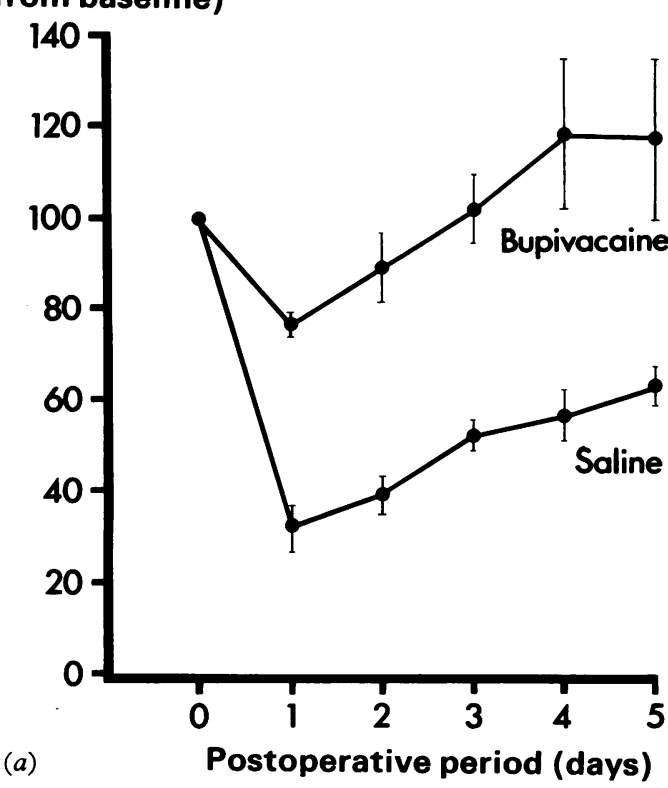

FVC

(\% change

from baseline)

130

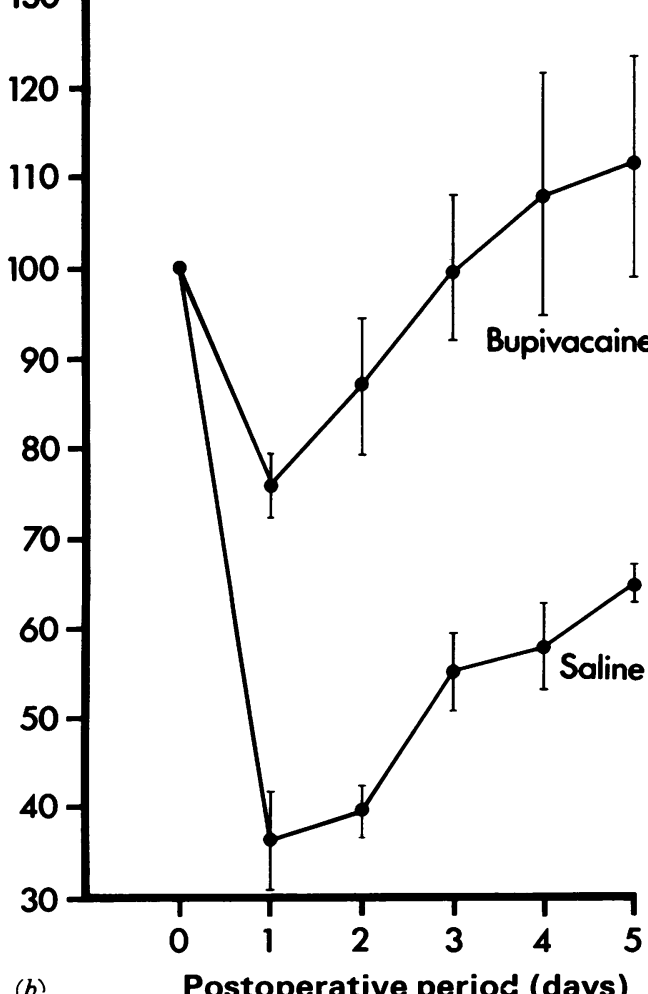

Table 2 Postoperative analgesic requirements in the first 48 hours

\begin{tabular}{|c|c|c|}
\hline & $\begin{array}{l}\text { Bupivacaine } \\
(n=8)\end{array}$ & $\begin{array}{l}\text { Saline } \\
(n=8)\end{array}$ \\
\hline $\begin{array}{l}\text { No opiate supplementation } \\
\text { Opiate requirement }\end{array}$ & 3 & 1 \\
\hline Median & $12.5 \mathrm{mg}^{\star}$ & $110 \mathrm{mg}^{\star}$ \\
\hline Mode & $00 \mathrm{mg}$ & $120 \mathrm{mg}$ \\
\hline $\begin{array}{l}\text { No rectal diclofenac } \\
\text { Rectal diclofenac }(100 \mathrm{mg})\end{array}$ & 7 & 1 \\
\hline $\begin{array}{l}\text { No of patients needing } \\
2 \text { suppositories }\end{array}$ & 1 & 1 \\
\hline $4 \quad$ & 0 & 6 \\
\hline
\end{tabular}

${ }^{\star} \mathrm{p}<0.01$.

\section{Discussion}

Major alterations in respiratory mechanics occur in all patients after anaesthesia and thoracotomy. One of the earliest changes in postoperative ventilatory mechanics is the substantial reduction in effort dependent lung measurements $\left(\mathrm{FEV}_{1}, \mathrm{FVC}, \mathrm{PEF}\right)$. This occurs before any change in functional residual capacity (FRC) can be detected. The decrease in FRC and the alveolar collapse that occur during anaesthesia readily worsen as a result of restrictive ventilation and an abnormal pattern of breathing due to postoperative pain. ${ }^{4}$ Once an airway closes or atelectasis develops air movement to that area ceases. Secretions tend to pool and become a focus for infection. Postoperative pulmonary complications correlate positively with the decrease in effort dependent lung measurements. ${ }^{12-14}$

Systemic opiates usually provide inadequate analgesia for pleurectomy and they may produce respiratory depression, drowsiness, nausea, and urinary retention. ${ }^{15}$ Epidural tech-

\section{PEF}

(\% change

from baseline)

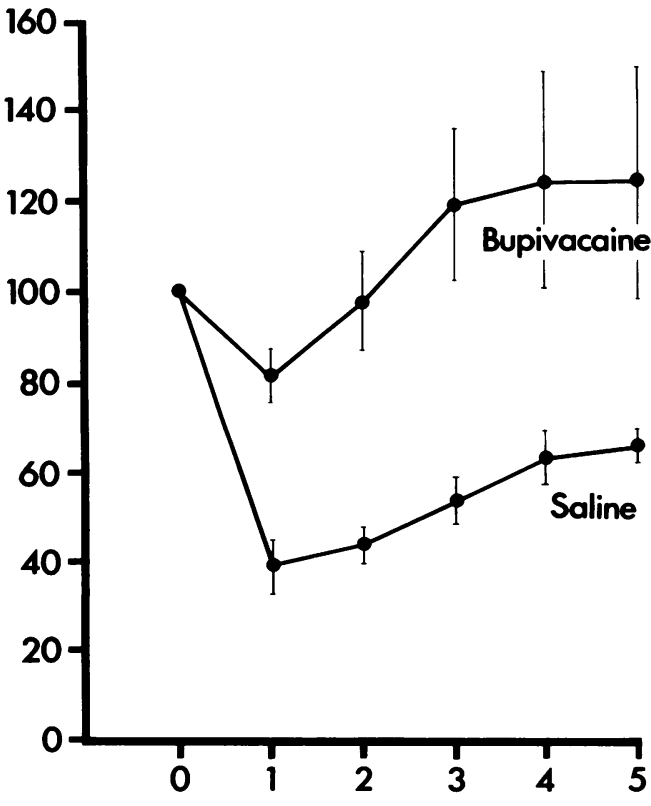

(c) 
niques, using local anaesthetic agents or opiates, provide effective analgesia and improve respiratory mechanics. Hypotension, muscle weakness, and urinary retention, however, are common after epidural block and the patients require increased nursing support. $^{16}$ Cryoprobe neurolysis of intercostal nerves does not include posterior primary rami and sympathetic fibres and hence does not provide adequate postoperative pain relief. ${ }^{17-19}$ In our study continuous intercostal nerve block with bupivacaine resulted in a smaller decline in FEV, FVC, and PEF at 24 hours than occurred in the control group and much more rapid recovery. Better postoperative analgesia resulted in considerably less need for narcotics. The patients were able to comply with vigorous physiotherapy easily because pain was minimal, and they required little sedation.

The mechanism of action of continuous intercostal nerve block administered extrapleurally depends primarily on its paravertebral spread. ${ }^{8}$ This allows the local anaesthetic agent to bathe not only the ventral nerve roots but also the posterior primary rami and afferent fibres of the sympathetic chain. The posterior primary rami supply the posterior ligaments, posterior spinal muscles, and overlying skin, which are traumatised at posterolateral thoracotomy. ${ }^{20}$ The pain from a thoracotomy also comes from visceral pleura and organs innervated by afferent fibres in sympathetic nerves.

We recently reported that continuous extrapleural intercostal nerve block provided safe, effective analgesia and substantial improvement in respiratory mechanics in $\mathbf{5 6}$ patients undergoing elective thoracotomy. ${ }^{8}$ These patients, however, had intact pleura. The present study was designed to determine whether the same results were possible in patients after pleurectomy. The technique of parietal pleurectomy was slightly modified to preserve the integrity of the parietal pleura, which covers the paravertebral space. Some of our analgesia would undoubtedly be due to intrapleural seepage of bupivacaine. Direct intrapleural bupivacaine has given variable degrees of postoperative pain relief after thoracotomy, however, in other studies. ${ }^{21-23}$

We have not encountered complications related to the technique or from continuous infusion of bupivacaine at the dosage described in this report. We conclude that continuous extrapleural intercostal nerve block is a safe and reliable method of providing analgesia after parietal pleurectomy, which helps to preserve lung function and is without important side effects.

1 Almind $M$, Lange $P$, Viskum $K$. Spontaneous pneumothorax: comparison of simple drainage, talc pleurodesis, and tetracyline pleurodesis. Thorax 1989;44:627-30.

2 Weeden D, Smith GH. Surgical experience in the management of spontaneous pneumothorax, 1972-82. Thorax 1983;38:737-43.

3 Harvey JE, Jeyasingham $\mathrm{K}$. The difficult pneumothorax. $B$ J Dis Chest 1987;81:209-16.

4 Craig DB. Postoperative recovery of pulmonary function Anaesth Analg 1981;60:46-52.

5 Fairley HB. Oxygen therapy for surgical patients. Am Rev Respir Dis 1980;122:37-44.

6 Bartlett RH, Brennan ML, Gazzangia AB, Hanson EL Studies on the pathogenesis and prevention of postoperative pulmonary complications. Surg Gynec Obs 1973;137:925-33.

7 Shulman M, Sandler AN, Bradley JW, Young PS, Brebner J. Post-thoracotomy pain and pulmonary function following epidural and systemic morphine. Anesthesiology 1984;61:569-75.

8 Sabanathan S, Mearns AJ, Bickford-Smith PJ, et al. Efficacy of continuous intercostal nerve block on post-thoracotomy pain and pulmonary mechanics. Br J Surg 1990;77:221-6.

9 Sabanathan S, Bickford-Smith PJ, Pradhan GN, Hashim $H$, Eng JB, Mearns AJ. Continuous intercostal nerve block for pain relief after thoracotomy. Ann Thorac Surg 1988;46:425-6.

10 Jenkins SC, Barnes NC, Moxham J. Evaluation of a handheld spirometer, the Respirodyne, for the measurement of forced expiratory volume in the first second $\left(\mathrm{FEV}_{1}\right)$, forced vital capacity (FVC) and peak expiratory flow rate (PEFR). Br J Dis Chest 1988;82:70-5.

11 Gaensler EA. Parietal pleurectomy for recurrent spontaneous pneumothorax. Surg Gynec Obst 1956;102:293-308.

12 Toledo-Pereyra LH, DeMeester TR. Prospective randomized evaluation of intrathoracic intercostal nerve block with bupivacaine on postoperative ventilatory function. Ann Thorac Surg 1979;27:203-5.

13 Ali J, Weisel RD, Layug AB, Kripke BJ, Hechtman HB. Consequences of postoperative alterations in respiratory mechanics. Am J Surg 1974;128:376-82.

14 Meyers JR, Lembeck L, Baue AE. Changes in functiona residual capacity of the lung after operation. Arch Surg 1975;110:576-83.

15 Catley DM, Thornton C, Jordan C, Lehane JR, Royston D Jones JG. Pronounced, episodic oxygen desaturation in the postoperative period: its association with ventilatory pattern and analgesic regimen. Anesthesiology 1985;63: $20-8$.

16 Smith G. Management of post-operative pain. Can Anaesth 1989;36:S1-4

17 Rooney SM, Jain S, McCormack P, Martini N, Godiner PL. A comparison of pulmonary function tests using cryoanalgesia and transcutaneous nerve stimulation. Ann Thorac Surg 1986;41:204-7.

18 Roxburgh JC, Markland CG, Ross BA, Kerr WF. The role of cryoanalgesia in control of post-thoractomy pain. Thorax 1986;41:233.

19 Orr IA, Keenan DJM, Dundee JW. Improved pain relie after thoracotomy: Use of cryoprope and morphine infusion. $B M J$ 1981;283:945-8.

20 Eason MJ and Wyatt R. Paravertebral thoracic blockreappraisal. Anaesthesia 1979;34:638-42.

21 Reiesstad F, Stromskag KE. Intrapleural catheter in the management of postoperative pain. A preliminary report. meg Anesth 1986;11:89-91.

22 Rosenberg PH, Scheinin BMA, Lepantalo MJA, Lindfor $O$. Continuous Intrapleural infusion of bupivacaine for analgesia after thoracotomy. Anesthesiology 1987;67 811-3.

23 Kambam JR, Hammon J, Parris WCV, Lupinetti FM Intrapleural analgesia for postthoracotomy pain and blood levels of bupivacaine following intrapleural injection. Can J Anaesth 1989;39:106-9. 